\title{
GRAUS DE RISCOS A QUE ESTÃO EXPOSTOS OS TRABALHADORES EM INSTITUIC̣ÕES HOSPITALARES Modelo de Intevenção de Enfermagem centrado nos riscos dominantes
}

Onedina Soares* Josefa Clelia Peixoto**

\begin{abstract}
RESUMO. As autoras apresentam um estudo descritivo sobre os graus de riscos a que estão expostos os trabalhadores de um hospital geral, localizado na Cidade do Rio de Janeiro. Apresentam outrossim, um Modelo de Intervenção de Enfermagem, centrado nos riscos dominantes, evidenciados na investigação empreendida.
\end{abstract}

\begin{abstract}
The authors present a study about the hazards, to which personal of a General Hospital at the City of Rio de Janeiro is exposed. Biological, physical and chemical risks were found. Based upon these findings, a model of nursing strategy was developed in order to avoid these risks.
\end{abstract}

\section{INTRODUC̣ÃO}

A saúde ocupacional constitui uma das atividades contidas nas Áreas Programáticas de Atuação do Sistema Nacional de Saúde, que figura dentre outras, ligadas ao meio ambiente.

0 posicionamento desta evidencia-se pela hierarquização que é dada, ao situá-la em primeiro plano.

Em se tratando de operacionalização na prática, a mesma atividade recebe a denominação de Higiene e Medicina do Trabalho, tão bem explicitada pela Portaria 3.214 de 08/06/1980, que regulamenta o disposto do Art. 200 da Consolidação das Leis do Trabalho CLT, com redação dada pela Lei no 5.514 de 22/12/1977 em sua NR-1 relativos à segurança, higiene, medicina do trabalho.

O conteúdo político e filosófico desta lei é revestido por uma amplitude de intervenção, exigência e preceitos, que envolvem Empresas Privadas, Públicas, Órgãos da Administração direta e indireta, bem como os Órgãos Legislativo e Judiciário, que possuem empregados regidos pela CLT.

Verifica-se, entretanto, que a rigidez do atendimento a esta Lei recai, tendenciosamente, nas Empresas
Privadas, enquanto que, paradoxalmente, as instituições de saúde não atendem aos preceitos emanados da referida Lei. 0 absurdo da falta de segurança dos empregados dos hospitais é evidente, situação esta inconcebível, uma vez que, segundo MORRONE \& OLIVEI$\mathrm{RA}$, as medidas de segurança, continuam sendo negligenciadas até hoje.

Assim sendo, considera-se de bom alvitre que sejam implantados programas de intervenção, principalmente pela enfermagem, tendo como fulcro os graus de risco presentes, para que o hospital possa realmente ser considerado conforme a ótica de BUNGLE, um local onde as atitudes positivas com relação a manutenção da saúde e a melhoria das condições de trablaho sejam enfatizadas e programadas.

Sabe-se dos riscos existentes nas unidades hospitalares, procedentes de sua própria constituição física e funcional, pouco se fazendo para a minimização e ou prevenção dos problemas dominantes, aspectos estes, destacados por SALVADOR (1985), ao registrar que os funcionários dos hospitais estão expostos, predominantemente a dois tipos de riscos: o das radiações ionizantes e o dos agentes biológicos.

\footnotetext{
* Professor do Curso de Enfermagem da Universidade do Rio de Janeiro. Doutor e Docente Livre pelo UFF. Assessor da Secretaria Municipal de Saúde. Enfermeiro de Trabalho.

${ }^{* *}$ Enfermeiro do Trabalho.
} 
Os motivos acima expostos serviram de fonte propulsora, para realização deste trabalho, tendo como diretriz os objetivos abaixo:

a) hierarquizar os graus de riscos contidos nas unidades existentes em uma instituição hospitalar autárquica, situada na Cidade do Rio de Janeiro.

b) apresentar uma proposição programática de Enfermagem, com ênfase nos graus de riscos dominantes na instituição estudada.

\section{ENFOQUE SITUACIONAL DOS GRAUS DE RISCOS DOS SERVIC̣OS DE SAÚDE}

Vários são os graus de riscos aos quais os servidores estão expostos, podendo-se evidenciar aqueles já configurados pela NR 15 Anexo 14, que os hierarquiza em dois tipos:

a) Grau máximo de risco, quais sejam, aqueles procedentes das próprias implicações dos trabalhos dos servidores e operações deles oriundas, como:

- contatos com pacientes em isolamento por doenças infecto-contagiosas, ou com objetos de seu uso, não previamente esterilizado;

- determinadas manipulações habituais em suas atividades, exemplificando-se a manipulação de tecidos, ossos, vísceras, sangues, glãndulas, couros, pelos e dejeções de animais portadores de doenças infecto-contagiosas, como carbunculose, brucelose e tuberculose;

- contatos com esgotos, galerias, tanques, lixo urbano, abrangendo inclusive a coleta e a industrialização.

b) Grau médio de riscos dos trabalhadores devido aos seus trabalhos e operações de permanente contato com pacientes, animais ou com material infecto-contagiante em hospitais, serviços de emergências, enfermarias, ambulatórios, postos de vacinação e ou estabelecimentos destinados aos cuidados de saúde humana.

Neste particular, convém também enfocar:

- os hospitais, ambulatórios, postos de vacinação e outros estabelecimentos destinados ao atendimento de animais;

- contato em laboratórios com animais destinados ao preparo de soro, vacinas e outros produtos;

- laboratório de análise clínica e histopatologia.

Dentre estes riscos, os mais encontrados no ambien-

te hospitalar, destacam-se, segundo os agentes;

- físicos - representados pelas irradiações ionizantes e não ionizantes, iluminação e umidade;

- químicos, incluindo névoas, poeiras, fumos, gases e vapores;

- biológicos, sendo os mais comuns os vírus e as bactérias.

De igual importância é a falta de manutenção de um sistema de treinamento desenvolvido pelo Servi- ço de Saúde Ocupacional, em larga escala e abrangente, a todos os trabalhadores em seus diversos níveis e categorias.

Como ficou patente, a simples permanência num hospital já implica numa exposição crítica aos riscos, indo somar-se aos procedimentos que, muitas vezes, exacerbam a periculosidade, além de outros contatos fortuitos.

\section{Tipo de Estudo}

O estudo foi analítico, procedentes da observação e levantamentos realizados.

\section{População}

A população compreendeu os chefes e enfermeiros atuantes num Hospital Estadual da Cidade do Rio de Janeiro.

\section{Amostra}

A amostra foi constituída de 20 (vinte) profissionais e 20 (vinte) elementos de equipe auxiliar, inclusive serviços de apoio e conveniados.

\section{Instrumentos Adotados}

Adotou-se como instrumento um Check List, contendo a especificação das unidades de risco, a existência ou não destas unidades e graus de risco.

Consideraram-se ainda neste instrumento aspectos pertinentes a observância da segurança e saúde ocupacional.

\section{Tratamento Estatístico}

0 tratamento estatístico envolveu o emprego de freqüência e percentual, sendo distribuídos os dados em tabela e gráfico.

\section{ANÁLISE E DISCUSSÃO DOS DADOS}

Iniciou-se o estudo, pela hierarquização dos riscos ocupacionais na Unidade Hospitalar, considerando-se o agrupamento de riscos e serviços neles incluídos, conforme expressado no Quadro Demonstrativo - Anexo II, onde se observa que existem 40 (quarenta) unidades expostas ao risco.

Prosseguiu-se o estudo, priorizando a freqüência dos graus de riscos, contidos nessas unidades, vendose sobressair como maior o grau III, havendo um certo equilíbrio numérico entre os graus I, II e IV, o que não invalida a ratificação de que o pessoal que exerce atividades no setor hospitalar estã sujeito a inúmeros riscos. Figura 1. 


\section{FIGURA 1}

PERCENTUAL DE GRAUS DE RISCOS NAS DIVERSAS UNIDADES DO HOSPITAL, REFLETINDO-SE NOS SERVIDORES DE SAÚDE

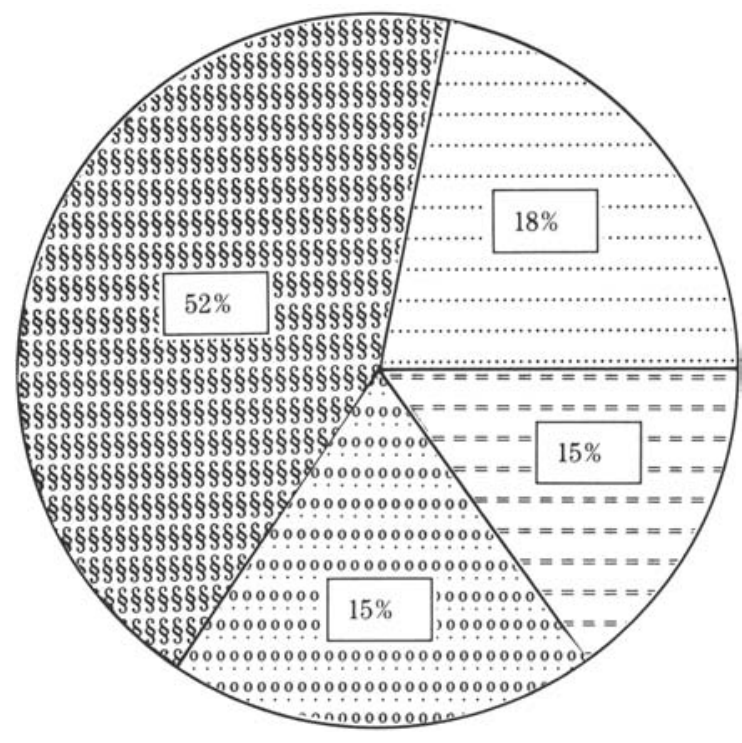

LEGENDA:

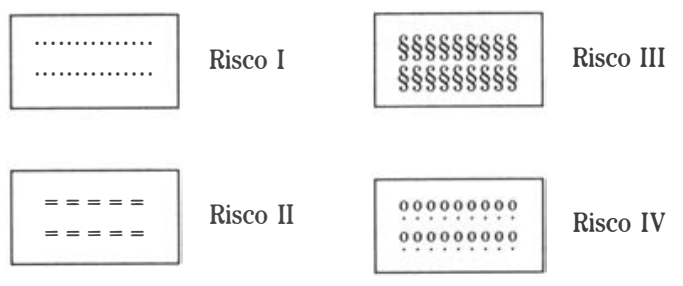

\section{CONCLUSÕES E SUGESTÕES}

Os dados obtidos permitem algumas conclusões e sugestões.

- É elevada a incidência de unidades de risco III na instituição estudada.

- Existe um equilíbrio numérico entre os riscos I, II e IV.

- O simples trabalhar neste hospital já evidencia a periculosidade a que estão expostos os trabalhadores de saúde.

As conclusões evidenciadas, implicam nas sugestões:

- Dinamização de maior observãncia das medidas de segurança e da saúde ocupacional do pessoal.

- Otimização da intervenção da Comissão de Infecção Hospitalar.

- Criação ou aprimoramento do Serviço de Saúde Ocupacional nesta Instituição.

- Vigilãncia e treinamento permanente do pessoal da Instituição.

\section{REFERÊNCIAS BIBLIOGRÁFICAS}

1. BRASIL. Ministério da Saúde. Legislação Brasileira, sobre infecção hospitalar. Brasília, D.F., 1985.

2. Ministério do Trabalho. Normas Regulamentadoras de Segurança e Medicina do Trabalho. Rio de Janeiro, 1980.

3. BRIONES, Francisco H. Doenças causadas por radiação ionizante. Manual de Medicina do Trabalho, Ed. MacGraw-Hill do Brasil Ltda. Rio de Janeiro, 1975.

4. LEIFORT, Ruth Miranda de Camargo et alii. Relação de TrabaIho e Saúde. O trabalho e a saúde do trabalhador. Anais do XXXVI Congresso Brasileiro de Enfermagem. Belo Horizonte, 1984.

5. SALVADOR, Juenir. Acidente de Trabalho em Hospital. Arquivos Brasileiros de Medicina Naval. Ano XLVI, n? 2, 1985.

6. SUNIS, Emílio. Riscos Ocupacionais. Manual de Higiene e Medicina do Trabalho. Ed. MacGraw-Hill do Brasil Ltda. Rio de Janeiro, 1975 


\section{ANEXO I}

\section{CHECK LIST}

I. UNIDADES DE RISCO

\begin{tabular}{|c|c|c|c|}
\hline \multirow{2}{*}{ ESPECIFICAÇÃO } & \multicolumn{2}{|c|}{ EXISTÊNCIA } & \multirow{2}{*}{$\begin{array}{c}\text { GRAUS } \\
\text { DE } \\
\text { RISCOS }\end{array}$} \\
\hline & SIM & NÃO & \\
\hline Anatomia Patológica & ) & ) & ) \\
\hline Arquivo Médico & ) & ) & ) \\
\hline Almoxarifado & ) & ) & ) \\
\hline Berçário Terapia Intensiva (BTI) & ) & ) & ) \\
\hline Central de Material e Esterilização & ) & ) & ) \\
\hline Cozinha Industrial & ) & ) & ) \\
\hline Centro Cirúrgico & ) & ) & ) \\
\hline Centro Obstétrico & ) & ) & ) \\
\hline Centro de Terapia Intensiva & ) & ) & ) \\
\hline Lavanderia Industrial & ) & ) & ) \\
\hline Laboratório de Análise e Clínica & ) & ) & ) \\
\hline Rouparia compreendendo confecção & ) & ) & ) \\
\hline Setor de Manutenção e Obras & ) & ) & ) \\
\hline - casa de máquinas & ) & ) & ) \\
\hline - caldeira & ) & ) & ) \\
\hline - carpintaria & ) & ) & ) \\
\hline - gerador & ) & ) & ) \\
\hline - obras e construções & ) & ) & ) \\
\hline - pintura & ) & ) & ) \\
\hline - serralheria & ) & ) & ) \\
\hline Serviço Medicina Nuclear & ) & ) & ) \\
\hline Serviço de Raio X Laboratório & ) & ) & ) \\
\hline Serviço de Fisioterapia & ) & ) & ) \\
\hline Serviço de Quimioterapia & ) & ) & ) \\
\hline Serviço de Limpeza & ) & ) & ) \\
\hline Serviço de Segurança & ) & ) & ) \\
\hline Serviço de Intervenção Especializada & ) & ) & ) \\
\hline - Pneumologia & ) & ) & ( \\
\hline - Dermatologia & ) & ) & ) \\
\hline Unidades de Internação & ) & ) & ) \\
\hline - Clínica Geral & ) & ) & ( \\
\hline • Clínica Cirúrgica & ( & ) & ( \\
\hline Unidade Ambulatorial Especializada & ) & ) & ) \\
\hline - Dermatologia & ( & ) & ( \\
\hline - Pneumologia & ( & ) & ( \\
\hline Unidade de Ambulatório Geral & ( & ( & ( \\
\hline Unidade de Pronto Socorro & ( & ( & ) \\
\hline
\end{tabular}




\section{OBSERVÂNCIA DA SEGURANÇA E DA SAÚDE OCUPACIONAL}

\begin{tabular}{|c|c|c|c|}
\hline \multirow{2}{*}{ ASPECTOS VISADOS } & \multicolumn{2}{|c|}{ EXISTÊNCIA } & \multirow{2}{*}{$\begin{array}{c}\text { GRAUS } \\
\text { DE } \\
\text { RISCOS }\end{array}$} \\
\hline & SIM & NÃo & \\
\hline Existência de Serviço de Saúde Ocupacional & ) & ) & ) \\
\hline $\begin{array}{l}\text { Existência de Pessoal Especializado em } \\
\text { Saúde Ocupacional e seus quadros }\end{array}$ & ) & ) & ) \\
\hline - Médicos & ( & ) & ( \\
\hline - Enfermeiros & ( & ) & ) \\
\hline - Aux. Enfermagem & ( & ) & ) \\
\hline - Engenheiro Segurança & ( & ) & ) \\
\hline $\begin{array}{l}\text { Existência de algum convênio com serviço de } \\
\text { Saúde Ocupacional }\end{array}$ & ( & ) & ) \\
\hline $\begin{array}{l}\text { Existência Organização da Comissão Interna } \\
\text { de Prevenção de Acidentes (CIPA) }\end{array}$ & ( & ) & ( \\
\hline - Médico & ( & ) & ( \\
\hline - Enfermeiro (a) & ) & ) & ) \\
\hline - Engenheiro & ) & ) & ) \\
\hline - Arquiteto & ) & ) & ) \\
\hline - Administrativo & ) & ) & ) \\
\hline - Outros & ) & ) & ) \\
\hline Existência de Setor de Educação em Serviço & ( & ) & ) \\
\hline Centro de Treinamento e Aperfeiçoamento & ( & ) & ) \\
\hline
\end{tabular}




\section{ANEXO II}

\section{QUADRO DEMONSTRATIVO DA HIERARQUIZAÇÃO DE RISCOS OCUPACIONAIS NA UNIDADE HOSPITALAR}

\begin{tabular}{|c|c|}
\hline $\begin{array}{l}\text { GRAU DE RISCO } \\
\text { OCUPACIONAL I }\end{array}$ & $\begin{array}{l}\text { GRAU DE RISCO } \\
\text { OCUPACIONAL II }\end{array}$ \\
\hline $\begin{array}{l}\text { - Departamento Pessoal } \\
\text { - Serviço de Contabilidade } \\
\text { - Processamento de Dados } \\
\text { - Setor de Licitação } \\
\text { - Setor de Finança } \\
\text { - Garagem e Parque de } \\
\text { - } \text { - Outracionamento de veículos } \\
\text { - }\end{array}$ & $\begin{array}{l}\text { Serviço de Comunicação } \\
\text { - Radiofonia } \\
\text { - Telefonia } \\
\text { Centro obstétrico } \\
\text { - Berçário } \\
\text { - Puerpério } \\
\text { - Pré-parto }\end{array}$ \\
\hline $\begin{array}{l}\text { GRAU DE RISCO } \\
\text { OCUPACIONAL III }\end{array}$ & $\begin{array}{l}\text { GRAU DE RISCO } \\
\text { OCUPACIONAL IV }\end{array}$ \\
\hline $\begin{array}{l}\text { 1. Hospital Geral e/ou Similares: } \\
\text { - Unidades de internação } \\
\text { - Unidade de pacientes externos, } \\
\text { compreendendo Ambulatório e Unidade de } \\
\text { Emergência. } \\
\text { - Centro de Terapia intensiva. } \\
\text { 2. Serviços Especializados: } \\
\text { - Hemodiálise } \\
\text { - Hemoterapia e Banco de Sangue } \\
\text { - Centro Cirúrgico } \\
\text { - Centro de Material e esterilização } \\
\text { - Serviço de Fisioterapia } \\
\text { 3. Serviços de Apoio e de Diagnóstico: } \\
\text { - Serviços de Raio X } \\
\text { - Servicos Hemodinãmica } \\
\text { - Serviços Farmácia } \\
\text { - Serviço Almoxarifado } \\
\text { - Serviço Documentação } \\
\text { - Serviço Médico } \\
\text { - Serviço Gráfico } \\
\text { - Serviço Rouparia, compreendendo confecção } \\
\text { - Serviço Lavanderia } \\
\text { - Transporte (ambulãncia) } \\
\text { 4. Serviços Administrativos: } \\
\text { - Portaria e recepção } \\
\text { - Serviço de segurança } \\
\text { - Serviço de limpeza e higienização } \\
\text { - Outros não identificados }\end{array}$ & $\begin{array}{l}\text { 1) Serviço de Medicina Nuclear incluindo } \\
\text { radioterapia e cobaloterapia } \\
\text { 2) Serviço de Cirurgia Experimental } \\
\text { 3) Serviço de Gasometria } \\
\text { 4) Serviço de Manutenção e Obras } \\
\text { 5) Serviço de Raio X } \\
\text { 6) Setor de Quimioterapia }\end{array}$ \\
\hline
\end{tabular}




\section{ANEXO III \\ MODELO DE INTERVENÇÃO DE ENFERMAGEM CENTRADO NOS RISCOS DOMINANTES}

Considerou-se de suma importância nortear a intervenção do Enfermeiro dentro dos aspectos conceituais contidos na própria definição de Enfermagem do Trabalho, procedente da Associação Americana de Enfermagem do Trabalho.

TIPO DE
ATIVIDADES

- Administrativas

- Técnicas

- Ensino

- Pesquisa

\section{ABRANGÊNCIAS}

- Planejamento e implementação das ações preventivas.

- Desenvolvimento e aperfeiçoamento de uma política de saúde capaz de intensificar a eficiência e a eficácia dos serviços prestados.

- Organização e manutenção dos serviços de saúde ocupacional.

- Supervisão do cumprimento das exigências contidas nas normas regulamentadas - NR de segurança e medicina do trabalho.

- Adoção de procedimento capaz de criar, manter e estimular o funcionamento da Comissão Interna de Prevenção de Acidente - CIPA, da Comissão de Controle de Infecção Hospitalar e do Serviço de Saúde Ocupacional.

- Atuação integrada com a equipe de segurança do trabalho.

- Adoção máxima das medidas de prevenção de acidentes.

- Melhoria das condições de trabalho com vistas a proteção dos trabalhadores.

- Implementação junto a equipe multidisciplinar de programas de prevenção e promoção da saúde dos trabalhadores e seus dependentes, bem como nas fases de reabilitação e integração ao trabalho.

- Proteção dos trabalhadores em unidades hospitalares ou similares, contra todo tipo de risco que possa prejudicar a sua saúde e assegurando-lhes condições de trabalho onde este se efetue.

- Treinamentos

- admissional

- periódico

- Participação em cursos de aperfeiçoamento ou especialização.

- Colaboração na melhoria do campo de trabalho para prática.

- Participar das pesquisas em geral.

- Fomentar e desenvolver pesquisas de Enfermagem.

Convém portanto realçar que a otimização das condições de trabalho nos hospitais está afeta aos profissionais de saúde e, principalmente, ao enfermeiro, cabendo-lhe, para tanto, o desempenho de funções nas áreas técnicas e administrativas e, mormente, na administração superior.

156 - Rev. Bras. de Enf., Brasília, 40 (2/3) abri/maio/jun./jul./ago./set., 1987 